\title{
BMJ Open The Tanzanian trauma patients' prehospital experience: a qualitative interview-based study
}

\author{
Kristin Kuzma, ${ }^{1}$ Andrew George Lim, ${ }^{2}$ Bernard Kepha, ${ }^{3}$ Neema Evelyne Nalitolela, ${ }^{4}$ \\ Teri A Reynolds ${ }^{1}$
}

To cite: Kuzma K, Lim AG, Kepha B, et al. The Tanzanian trauma patients' prehospital experience: a qualitative interview-based study. BMJ Open 2015;5:e006921. doi:10.1136/bmjopen-2014006921

- Prepublication history for this paper is available online. To view these files please visit the journal online (http://dx.doi.org/10.1136/ bmjopen-2014-006921).

Received 15 October 2014 Revised 6 February 2015 Accepted 27 February 2015

CrossMark

For numbered affiliations see end of article.

Correspondence to Dr Kristin Kuzma; kckuzma@gmail.com

\section{ABSTRACT}

Objectives: We sought to characterise the prehospital experience of Tanzanian trauma patients, and identify barriers and facilitators to implement community-based emergency medical systems (EMS).

Settings: Our study was conducted in the emergency department of an urban national referral hospital in Tanzania.

Participants: A convenience sample of 34 adult trauma patients, or surrogate family members, presenting or referred to an urban referral emergency department in Tanzania for treatment of injury, participated in the study.

Interventions: Participation in semistructured, iteratively developed interviews until saturation of responses was reached.

Outcomes: A grounded theory-based approach to qualitative analysis was used to identify recurrent themes.

Results: We characterised numerous deficiencies within the existing clinic-to-hospital referral network, including missed/delayed diagnoses, limited management capabilities at pre-referral facilities and interfacility transfer delays. Potential barriers to EMS implementation include patient financial limitations and lack of insurance, limited public infrastructure and resources, and the credibility of potential first aid responders. Potential facilitators of EMS include communities' tendency to pool resources, individuals' trust of other community members to be first aid responders, and faith in community leaders to organise EMS response. Participants expressed a strong desire to learn first aid.

Conclusions: The composite themes generated by the data suggest that there are myriad structural, financial, institutional and cultural barriers to the implementation of a formal prehospital system. However, our analysis also revealed potential facilitators to a first-responder system that takes advantage of close-knit local communities and the trust of recognised leaders in society. The results suggest favourable acceptability for community-based response by trained lay people. There is significant opportunity for care improvements with short trainings and low-cost supply planning. Further research looking at the effects of delay on outcomes in this population is needed.

\section{Strengths and limitations of this study}

- This is the only qualitative interview-based study conducted with patients and their family members about the experience of obtaining care after a traumatic injury in a country without either an organised trauma or prehospital care system.

- The study is limited to a single urban centre with a small sample size, which limits the generalisability. While the study is not intended to be a representative population study, participants varied widely in injury severity, gender and age.

- A second limitation is that interviews were conducted in Swahili, however, thematic analysis was conducted in English and, therefore, inaccurate interpretation is possible.

\section{BACKGROUND}

Injury remains among the leading causes of morbidity and mortality worldwide, particularly in low-income and middle-income countries (LMIC). According to the WHO, 5.8 million people die from injury every year, and $90 \%$ of trauma-related deaths occur in LMIC. In addition, because trauma disproportionately impacts a working age male population, it has substantial economic impact in these countries. ${ }^{1}{ }^{2}$ Over one million people perish, and 20-50 million are injured annually from road traffic injuries alone. Road traffic accidents are the second leading cause of death among those aged 529 and third among those aged 30-44 globally, and these numbers are projected to rise substantially as a result of increasing motorisation in LMIC.

The growing need for rapid medical response in LMIC has led to the development of emergency care systems tailored to locally available resources. Emergency care is comprised of prehospital and facility-based components. The prehospital components include recognition, triage, management and transportation. ${ }^{3}{ }^{4}$ While there is debate about 
which aspects of prehospital care reduce morbidity and mortality in injured patients, several studies have shown a reduction in mortality among patients within organised trauma systems. ${ }^{5}$ The systematic training of lay providers has also been shown to be effective in several LMIC. In rural Iraq and Cambodia, significant mortality reduction was seen with paramedic and lay-responder training. ${ }^{6-8}$ The emergency first aid responder system, a model utilising community-based responders in South Africa, was found to be effective and well received. ${ }^{9}$ Studies from South Africa, Ghana and Uganda have demonstrated good retention of first aid skills among taxi drivers, truck drivers and police officers after short trainings, as well as an increase in their willingness to aid trauma victims. ${ }^{9-12}$ In Ghana, truck drivers were successfully taught basic stabilisation skills, including haemorrhage control, splinting, makeshift cervical spine and airway protection techniques. ${ }^{12} 13$

Tanzania, as in other LMIC, faces a profound provider shortage and lacks formal prehospital emergency medical services (EMS). ${ }^{14-16}$ It is a country of 44.8 million people, with two doctors per 100000 . Doctors make up only $2 \%$ of the Tanzanian healthcare workforce, and in 2004, there were 822 doctors to serve the entire country. The distribution of trained medical professionals is uneven, with 25 doctors per 100000 people in Dar es Salaam, compared to $1.3 / 100000$ in outlying areas. Nurses and midwives make up $27 \%$ of the healthcare workforce and there are only 20 nurses per 100000 population. ${ }^{17}{ }^{18}$ Furthermore, the large majority of hospitals lack the basic physical infrastructure and tools to treat patients. ${ }^{19}$

Emergency medicine specialist training is relatively nascent in Tanzania, with the first graduates entering the workforce in 2013; thus, most emergency care in the country is provided by non-specialists (most often nonphysicians) without dedicated emergency care training. The healthcare system is arranged to filter patients from peripheral low-level facilities to referral hospitals. Dispensaries and healthcare centres can refer up to district hospitals, which then refer on to 1 of over 20 regional hospitals or four specialised referral hospitals.

Most district hospitals have medical doctors on staff, but much of the care is provided by nurses and clinical officers. ${ }^{15} 17$ In most cases, patients must first secure a referral slip from a district or subdistrict facility prior to being seen in a higher-level referral hospital. In some cases, patients may be taken to district hospitals where no care is delivered, only to receive a referral to the tertiary care hospital. Acutely injured patients may also be referred directly to a higher level facility by police, but in some cases, must proceed first to the police station to make a report. There are ambulances available for interfacility transfer, but there is no public field response system.

Muhimbili National Hospital (MNH), in Dar es Salaam, is one of the four public tertiary referral hospitals in Tanzania and is the ultimate national referral hospital for trauma. MNH emergency department (ED) receives about $100-150$ patients daily, of which $25 \%$ are trauma patients. ${ }^{20}$ Healthcare costs are highly subsidised and are based on patient income. The majority of patients pay 10000 TSH (US\$6.25) for a consultation and an additional 10000 TSH for admission. (The average per capita income in Tanzania is \$313). The elderly, those under 5, and those with HIV or tuberculous receive free care and are defined as 'exempt by policy.' Other exceptions include government employees who have health insurance that includes family coverage. Dar es Salaam has experienced explosive growth over the past decade with exponentially increasing motorisation, and injury represents a substantial proportion of the presentations to the MNH ED. ${ }^{20}$

\section{Gaps in the literature}

Little is known about the prehospital experience of trauma patients in LMIC, including how the injured are treated and transported to healthcare facilities. Competition for the limited healthcare dollars available in Tanzania is fierce; therefore, prehospital care systems that are effective and affordable are needed. These systems must be supported by the communities they serve to be sustainable, rather than just adopting systems from high-income countries-a strategy that has proven to be thus far unsuccessful.

\section{Study objectives}

This is an interview-based qualitative study characterising how trauma patients are transported and treated prior to arrival to a Tanzanian tertiary care hospital. The study aimed to identify barriers and facilitators to the implementation of EMS systems, including community-based first aid response. Interviews focused on patient experience from the time of injury to their arrival at the tertiary facility, including prefacility as well as peripheral facility experiences.

\section{METHODS}

\section{Study participants and data collection}

A convenience sample of 34 adult trauma patients presenting to the MNH ED between 1 July 2013 and 1 August 2013 participated in semistructured interviews.

Interviews were conducted in the $\mathrm{ED}$ after treatment and stabilisation, but before transfer to inpatient services. Five patients were deemed too ill to be interviewed, and an accompanying family member was asked to participate as a surrogate. Informed consents and interviews were conducted by a Tanzanian physician in Swahili. An interview guide was developed that served to initiate topics; questions were evolved through an iterative process as researchers gathered information.

Interviews were divided into three components: demographics, current injury experience and views on the potential for community-based care in Tanzania. Demographic information included patient age, gender, ethnic identity, rural or urban residency, education level 
and distance from $\mathrm{MNH}$ in terms of transport time. Questions about the patient's current experience covered the events leading up to arrival at the trauma centre, the type of treatments received and how cost was managed. The community-based care component of the interview addressed current community-based management of injury and participant views on the possibility of injury care provided by lay people, including taxi drivers, community-designated responders and police. Participants were also asked about their views on the possibility of ambulance dispatch service. Interviews generally took $30-40 \mathrm{~min}$. A deidentified written record of interviews was kept.

\section{Data analysis}

A grounded theory-based approach to qualitative analysis was used for the ultimate generation of theoretical constructs. ${ }^{21}$ Interview notes were reviewed iteratively for dominant codes or themes, and interviews were continued until participants offered no new themes and saturation was achieved. Codes and themes were tabulated, categorised and formed the foundation for larger analytic themes, which will be presented in the discussion section.

Inter-rater reliability was enhanced, with multiple authors independently responsible for qualitative data analysis (AGL and KK), with reasonable concordance of descriptive codes and also categorised analytic themes.

\section{RESULTS}

Quantitative data have been presented in table format. Table 1 contains demographic characteristics of the study participants including age, gender, residence, education level and their source of payment for healthcare or insurance coverage. The mechanisms of injury and types of injuries are listed in table 2. Table 3 presents the current community resources called on after an injury and perceived trustworthiness of various potential responders.

\section{Characterisation of the existing healthcare referral network}

Before discussing the barriers and facilitators to developing a true EMS first-response system, we asked about participants' experience with the current referral system between clinics and local hospitals, and the tertiary care trauma centre of Dar es Salaam. Table 4 for categorisation of major themes.

Muhimbili ED acts as a tertiary or secondary level referral centre for the outlying regions around Dar es Salaam. All but two patients $(94 \%)$ were referred by an outside health facility (see table 1). Four patients were transferred to $\mathrm{MNH}$ days after presenting to peripheral facilities. Nine were discharged from peripheral facilities prior to presentation to MNH. Twenty-one patients were seen in a peripheral facility and transferred to $\mathrm{MNH}$ by that facility's transfer ambulance, while 11 received a

\begin{tabular}{|c|c|}
\hline Characteristic, N (\%) & Interview, N=34 \\
\hline Patient age, years (median) & $18-73(32)$ \\
\hline Gender female & $10(29)$ \\
\hline \multicolumn{2}{|l|}{ Residence, N (\%) } \\
\hline Urban/suburban & $28(82)$ \\
\hline Rural & $7(18)$ \\
\hline \multicolumn{2}{|l|}{ Insurance, N (\%) } \\
\hline Government insurance* $(\%)$ & $4(12)$ \\
\hline Rural health insurance $\dagger(\%)$ & $2(6)$ \\
\hline Exempt by policy $¥$ (\%) & $1(3)$ \\
\hline Self-pay (\%) & $27(79)$ \\
\hline \multicolumn{2}{|c|}{ Education level of interviewees, $\mathrm{N}(\%)$} \\
\hline None & $1(3)$ \\
\hline Primary & $23(67)$ \\
\hline Partial secondary & $3(9)$ \\
\hline Secondary & $3(9)$ \\
\hline College & $4(12)$ \\
\hline \multicolumn{2}{|c|}{$\begin{array}{l}\text { *Government insurance-only for employees in government jobs. } \\
\text { †Rural community health-residents of village receive free local } \\
\text { health clinic care. } \\
\text { fExempt by policy. Those under } 5 \text { years of age, the elderly, and } \\
\text { tuberculous and HIV patients receive government sponsored } \\
\text { health insurance. }\end{array}$} \\
\hline
\end{tabular}

referral from the initial facility, but were not provided transport.

The following subject case studies highlight the current gaps in health delivery that exist with the existing referral system-diagnoses are missed, delays in care and transfer frequently occur, and poor patient outcomes manifest, which could have been avoided, due to limited capabilities at pre-referral centres.

\section{Missed or delayed diagnoses}

The time from injury to arrival at MNH ranged from $1 \mathrm{~h}$ to 9 days. Patients who were referred directly from outlying facilities arrived at $\mathrm{MNH}$ within $45 \mathrm{~min}$ to 5 days, though most arrived within the first $24 \mathrm{~h}$ of injury.

Causes for delay included undiagnosed injuries and delayed availability of transportation.

Three patients in the study were discharged from one hospital with unrecognised injuries and subsequently went to other hospitals where their injuries were diagnosed.

Case 1: A 20-year-old pedestrian struck by a car and sustaining a head injury was observed in a district hospital until he awoke a day later and was discharged home. Since he was unable to urinate, he went by taxi to another district hospital where a urinary catheter was placed, and he was told to return in 7 days. Instead, his family brought him to $\mathrm{MNH}$, where a bedside ultrasound revealed intraperitoneal fluid, with an eventual diagnosis of pelvic fracture complicated by urethral injury. Further imaging revealed injuries to his chest and spine.

Case 2: A 70-year-old woman was struck by a car while walking. The driver took her to the district hospital where a pelvic ramus fracture was diagnosed by X-ray. She was sent home but developed shortness of breath over 3 days. She walked to another district hospital and 
Table 2 Injury characteristics*

\begin{tabular}{lc}
\hline Mechanism of injury, N (\%) & Patients, $\mathbf{N}=\mathbf{3 4}$ \\
\hline Motor vehicle & $13(38)$ \\
Motorcycle accident & $8(23)$ \\
Pedestrian versus automobile & $4(12)$ \\
Assault & $2(5)$ \\
Gunshot wound & $1(2)$ \\
Fall & $5(15)$ \\
Burn & $1(2)$ \\
Known injury types, $\dagger$ N (\%) & \\
Head injury & $15(44)$ \\
Spinal cord or back injury & $3(9)$ \\
Thoracic injury & $5(15)$ \\
Pelvic fracture & $5(15)$ \\
Open fractures & $10(29)$ \\
Closed fractures & $13(38)$ \\
Burns & $1(2)$ \\
Transportation to first healthcare facility & N (\%) \\
Private car & $12(35)$ \\
Car Taxi/auto rickshaw & $9(26)$ \\
Motorcycle taxi & $2(6)$ \\
Bus & $2(6)$ \\
Carried & $2(6)$ \\
Unknown & $7(20)$ \\
First healthcare facility, N (\%) & \\
Dispensary & $4(12)$ \\
Health centre & $7(20)$ \\
District hospital & $12(35)$ \\
Private hospital & $6(17)$ \\
Military hospital & $3(8)$ \\
Direct to MNH & $2(6)$ \\
\hline
\end{tabular}

*Owing to limited diagnostic testing and the small size of this cohort, these numbers likely underestimate the true rate of injuries and do not reflect the distribution of injuries in the department as a whole.

†There may be more than one injury type per individual. Identification of injuries is limited by lack of imaging, so this information may reflect physical exam, limited plain film use or ED ultrasound findings.

ED, emergency departement; MNH, Muhimbili National Hospital.

was then referred to $\mathrm{MNH}$, where she was found to be hypoxic, and diagnosed with rib fractures and pulmonary contusions.

Case 3: A 28-year-old motorcyclist was crushed between his bike and a truck, sustaining open ankle and metatarsal fractures. He was brought by taxi to a health centre where X-ray facilities were closed for the weekend. He was given an analgaesic and told to return in three days when the X-ray would be available. On return, his foot had become infected and necrotic, and he was transferred to $\mathrm{MNH}$.

\section{Limited management capacity at peripheral facilities}

Imaging for head injuries is limited by lack of physical resources and the cost to patients of CT. Among 15 patients with head trauma, 2 were diagnosed with basilar skull fracture and 9 had prolonged loss of consciousness (hours to days) or persistent altered mental status. In two cases, patients with major head injuries were kept at district hospitals for several days until they awoke and
Table 3 Community-based assistance

\begin{tabular}{lc}
\hline $\begin{array}{l}\text { Current emergency } \\
\text { assistance, N (\%) }\end{array}$ & Interviews, \\
\hline Family only & $4(12)$ \\
Neighbours assist & $21(62)$ \\
None & $14(41)$ \\
Range of neighbourly assistance, N (\%) & \\
$\quad$ Neighbours assist with & $20(56)$ \\
transportation & \\
Neighbours assist with cost & $4(12)$ \\
$\quad$ Neighbours assist with first aid & $2(6)$ \\
Trust to give first aid response, N (\%) & \\
Neighbours/known only & $13(38)$ \\
Religious group & $6(17)$ \\
Police & $5(15)$ \\
Taxi drivers & $3(9)$ \\
Trained laypeople & $10(29)$ \\
$\quad$ Doctors/nurses/professionals & $1(2)$ \\
Trust to organise first aid response, N (\%) & \\
Government & $3(9)$ \\
Religious leaders & $6(12)$ \\
Ten-cell leader & $11(32)$ \\
Village or ward executive & $4(12)$ \\
Vikoba game purse holder & $1(2)$ \\
Police & $1(2)$ \\
Red cross or private aid group & $3(9)$ \\
Hospital & $1(2)$ \\
No opinion & $4(12)$ \\
\hline *Participants offered more than one response. & \\
&
\end{tabular}

were noted to have persistent confusion; only then were they transferred by ambulance to $\mathrm{MNH}$ for neurosurgical evaluation.

Participants described that initial treatment at subdistrict facilities was very limited. Six patients were referred with no treatment, and five received a single dose of analgesics with a referral on to a district hospital or $\mathrm{MNH}$. Rarely were fractures splinted, and most lacerations went unrepaired. Even at district hospitals, fewer

Table 4 Major analytic themes

\begin{tabular}{ll}
\hline $\begin{array}{l}\text { Characterisation of the } \\
\text { existing healthcare referral } \\
\text { network }\end{array}$ & $\begin{array}{l}\text { Missed or delayed } \\
\text { diagnoses } \\
\text { Limited management } \\
\text { capacity at peripheral } \\
\text { facilities } \\
\text { Interfacility transfer delays } \\
\text { Patients' financial } \\
\text { limitations } \\
\text { Limitations of public } \\
\text { infrastructural resources } \\
\text { Credibility of potential first } \\
\text { Barriers to EMS care } \\
\text { implementation }\end{array}$ \\
& $\begin{array}{l}\text { Communal pooling of } \\
\text { resources }\end{array}$ \\
Facilitators to EMS care & Intercommunity trust for \\
access & first aid responsibility \\
\hline EMS, emergency medical systems.
\end{tabular}


than $50 \%$ of fractures were splinted and none of the open fractures were irrigated. When used, splints were constructed from cardboard boxes or branches. Only two of five femur fractures had any type of splint applied, and no traction was placed. Antibiotics were generally not given.

\section{Interfacility transfer delays}

Tanzania's referral system theoretically includes free ambulance service for the transfer of patients from peripheral to higher level facilities, though significant delays may occur due to the limited number of ambulances and the cost of fuel. Participants reported that transfer times varied from within the hour to several days. One rural bicyclist struck by a motorcycle sustained femur, tibia and fibula fractures. Neighbours splinted his leg with branches and carried him on foot $30 \mathrm{~min}$ to a local dispensary. A request for an ambulance was made to the district hospital but was denied, so he was brought after a $4 \mathrm{~h}$ motorcycle taxi ride to the district hospital where the X-ray machine was broken. He then waited $24 \mathrm{~h}$ for an ambulance to bring him to $\mathrm{MNH}$.

In another case, a woman with a severe head injury remained in a rural district hospital for 4 days until the neighbours collected funds to pay 300000 shillings (US $\$ 187$ ) illegally demanded by the ambulance driver for the $5 \mathrm{~h}$ transfer to $\mathrm{MNH}$.

One 23-year-old man was injured falling backward from a truck. His family treated him with warm baths for his sore neck, and he experienced progressive weakness until he was unable to ambulate. His family took him to a rural district hospital, where he was treated for malaria, then told that he needed to go to $\mathrm{MNH}$ for a cervical spinal cord injury. The patient was discharged home until his family could arrange transportation, rather than transferring him by ambulance. The family collected money over several days and brought him to Dar es Salaam by bus, and then in the bed of a truck, to $\mathrm{MNH}$. Nine days after his injury he arrived, quadriplegic, at $\mathrm{MNH}$ for neurosurgical evaluation.

Care during ambulance transport was reportedly minimal-patients were rarely transported with clinical personnel. Even when nurses were present for transport, they sat in the front of the ambulance, while patients remained unattended in the back.

These case reports from respondents underscore the consequences and need for EMS response in the urban areas of Dar es Salaam. The next section will discuss the potential barriers to implementation of such systems, as perceived by interviewed participants.

\section{Barriers to EMS care implementation}

Major barriers to the implementation of EMS, either community-based or government organised, included the financial status of patients and limitations of healthcare insurance, poor transportation and other public infrastructure, and the level of technical credibility of layperson first responders.
Patients' financial limitations

As illustrated in table 1, the majority of participants did not have any health insurance. Only four respondents $(12 \%)$ were covered by government insurance. Two patients reported having public insurance covering care at rural clinics only, and they paid out-of-pocket for hospital care. Among those covered by private funds, 13 (48\%) had costs covered by family, 1 pedestrian's costs were covered by the driver of the vehicle that struck her, and $6(22 \%)$ had employers cover their costs. Seven (25\%) were unsure how the costs had been covered.

Participants who covered their own costs paid exorbitant prices for healthcare compared with their incomes. Although most participants were unable to give direct cost information since it was covered by family or bystanders, three reported that transportation cost as much as healthcare fees, and overall cost constituted a significant proportion of the average Tanzanian per capita annual income of US\$313. Furthermore, patients are required to pay out-of-pocket for expensive CT scans, so few are performed, and most injuries are diagnosed either clinically, by X-ray, or by ultrasound. Most patients paid approximately 30000-60000 shillings (US\$18-US\$36) for healthcare prior to arrival at MNH. One patient was charged 250000 shillings (US\$156) at a private hospital for his isolated tibia-fibula fracture. Another patient who was seen in four facilities due to misdiagnosis of an open foot fracture estimated his transportation and treatment cost at 180000 shillings (US\$112).

\section{Limitations of public infrastructural resources}

Limited public resources in transportation and other infrastructure may further limit the implementation of true first-responder EMS systems. Respondents cited a variety of primary points of healthcare contact prior to being transported to $\mathrm{MNH}$ for definitive care. Transportation to the first healthcare facility was usually by private vehicle (35\% of patients) or some form of private motorised taxi service (see table 2). Seven patients and their families did not know how they arrived at the first facility. Rural participants reported that car taxis are rare and motorcycle taxis more common. One elderly woman riding on a motorcycle taxi sustained a basilar skull fracture and a forearm fracture; she was subsequently transferred to another motorcycle taxi for transport to a district hospital.

While many participants supported the idea of ambulance service, there were differing opinions. When asked about the potential efficacy of first-response ambulance systems, many participants were sceptical. About a quarter of participants thought it would be too expensive. Four said it would take too long to get an ambulance to the scene, citing traffic congestion, and that taxis or auto rickshaw would be faster. Participants who felt that an ambulance service would be a good idea believed it could be the same or cheaper than a taxi, with the assumption that compassionate ambulance personnel would not charge much. Some participants reported a lack of faith 
in the automobiles used as ambulances, as they were at times unreliable and prone to failure. Most people expected they would pay a 'bit more' than a taxi. One person was concerned that ambulances would create an opportunity for drivers to extort bribes for transport.

Furthermore, participants reported delays to ED arrival caused by the activities of public institutions such as the police and fire departments, causing general mistrust to municipal response. Participants indicated that motor vehicle accidents must be reported to police. In the case of road traffic injury, police are often nearby directing traffic at busy intersections. Participants reported, however, that a detour to a police station may significantly delay care when police are not on the scene, as even severely injured patients may be transported to a police station prior to a care facility. In one case, a motorcyclist struck by a car and sustaining facial injuries and arm fractures reported being taken by the driver of the car to the police station to make a report prior to being taken to a private hospital. If available, family members may make a police report while an injured patient is transported to a hospital.

\section{Credibility of potential first aid responders}

Interviewed participants had varying opinions on the level of medical knowledge and technical training they expected of potential first aid respondents. Generally, few lay people had exposure to first-responder medical skills (see table 3). Only two respondents knew people in their community who had first aid training. With the exception of one participants who was splinted by neighbours, no participants reported community-based delivery of clinical care.

Generally, respondents felt most comfortable within known circles of trusted members of their communities. When asked who people would trust to provide first aid to them or their family, some participants (38\%) preferred care to come either directly from family or known neighbours. Only three people felt it would be appropriate to train police or taxi drivers, and many did not trust them to provide care. Participants felt that police would be 'too busy' and 'too bureaucratic,' and that taxi drivers 'aren't compassionate' and would be 'too focused on collecting money.'

Participants were asked if they had a religious preference regarding the person providing first aid to them or their family. A significant number of participants felt any religious group would be acceptable, but two respondents preferred Christians (overall, Tanzanians report affiliation with Islam (40\%), Christianity $(35 \%)$ and Animism $(20 \%)) .^{22}$ Though everyone agreed with the statement that 'many people use traditional healers', none of the respondents reported going to traditional healers, and no participants felt that traditional healers would be a good choice for first aid training.

Finally, there were a few participants who believed that not all bystanders could be trusted due to the prevalence of theft. Three patients, initially unconscious, reported that bystanders robbed them of wallets and cell phones. Several participants described this as a common phenomenon.

\section{Facilitators to EMS care access}

Despite the formidable challenges to the implementation of EMS as described above, there are myriad factors at play that may facilitate a community-based firstresponse system. Several practices exist among local communities that serve to meet the needs of emergency medical response on an ad hoc basis. This includes the communal pooling and sharing of resources, including volunteering to give rides to the injured. Furthermore, the topic of trust was explored-both of participants' self-confidence in their ability to be first responders, as well as trust in community leaders to organise first responders and provide the required training.

\section{Communal pooling of resources}

Participants reported that financial and logistical support for traumatic injuries often came from other members of their social communities-friends, family or the individuals responsible for causing the trauma. When asked how emergencies were handled in their communities, $56 \%$ reported that neighbours assisted in arranging transportation; $12 \%$ reported that communities would pool money to assist with cost (see table 3).

Several motorcycle taxi drivers considered their fellow drivers an important resource for transportation and financial support in the case of injury. One particularly cohesive group of motorcycle taxi drivers had pooled funds to create a form of insurance, which is distributed to injured drivers as needed.

Bystanders and neighbours played a major role in response to accidents. Participants reported a strong feeling of responsibility and willingness to care for people injured in accidents, though only one patient reported having prior first aid training. Participants indicated that, in general, pedestrians hit by vehicles are considered the responsibility of the vehicle driver, who should transport the victim to the hospital and pay for healthcare costs.

\section{Intercommunity trust for first aid responsibility}

The majority of respondents reported a willingness to learn first aid $(n=26,76 \%)$. Most people who did not want to be trained were afraid of harming someone or were fearful of the sight of injuries. Only one person reported being afraid to help strangers. About one-third of those willing to learn said they would want to wear personal protective equipment.

Participants were asked if there were some people they would not want to treat, such as those beaten in vigilante retribution for theft. Among those who said they were willing to be trained, all 34 said they would be willing to administer first aid to a victim beaten for suspected theft.

Overall, gender was not an issue in terms of who participants felt should be trusted to be a first aid responder: 32 participants said that gender would not be important to them. As one respondent stated, 'better that a man should help a woman, than she should die.' 
There was less unanimity in terms of the local leadership being responsible for organising and training first aid responders. In total $32 \%$ considered the '10-cell leader' the best choice. Ten-cell leaders are the first level of governmental leadership groups, which coalesce to form hierarchical levels of leadership and representation within the government: 10 cells answer to wards, which form districts, ultimately organised into regions of the country. Only three participants felt the larger government would be a good choice for organising first aid response. One participant, a bank executive whose company used ward (a unit above the 10-cell, governing approximately 1000 people) leaders to communicate with the community felt that they would be a good choice for organising. One person suggested the vikoba 'purse holder' would make a good leader. Vikoba is an informal savings plan in the form of a game in which a group of neighbourhood families each contribute funds to a pot, which is distributed to a different family each month to facilitate large purchases.

Six individuals $(12 \%)$ felt that religious groups would also be good at organising training and response, and that 'compassion' would make religious affiliates good first responders. In three communities cited by interviewees, religious groups were reported to already play a key role in first aid response.

\section{Limitations}

This was a small study of patients in a single facility, which limits its generalisability. We do not claim to represent the overall distribution of injury types or severity in this paper or to determine the relative frequencies of specific events. We do believe that the qualitative methodology is well matched to the goal of characterising a range of patient experiences. There is almost no prior literature on the participant, and we hope that our results will serve to facilitate further research on the specific questions they evokes.

Interviews were conducted in Swahili and translated to allow thematic analysis in English, which may have introduced inaccuracies. To mitigate this effect, the data were analysed in conjunction with the bilingual local physicians who conducted the interviews. Finally, while this is a small sample, we included participants from a range of educational and socioeconomic backgrounds.

\section{CONCLUSION}

The composite themes generated by the data suggest that there are myriad structural, financial, institutional and cultural barriers to the implementation of a formal prehospital system. However, our analysis also revealed potential facilitators to a first-responder system that takes advantage of close-knit communities and the trust of recognised local leaders.

Our study participants were primarily urban residents and, consistent with prior literature, the victims were predominantly young and men. ${ }^{1} 23$ The overwhelming majority $(79 \%)$ paid for their care out-of-pocket, which has significant implications for planning discussions around emergency care availability and access. Most were victims of road traffic accidents, which is consistent with previously published literature from the same facility. ${ }^{20}$

Many of the victims sustained complex injuries for which even simple interventions, such as splinting and antibiotics, were rarely performed. As these are inexpensive interventions, this finding suggests an opportunity for substantial care improvements with short-term training and low-cost supply planning.

This preliminary study suggests targets for further investigation into how EMS can be best implemented in Tanzania:

1. Overall, our study identified a range of distinct causes for delays in transfer. While some delays would be mitigated by infrastructure improvements (more ambulances and improved dispatch), others (driver extortion) suggest the need for improved personnel oversight and accountability. Some delays resulted from delayed recognition of the presence or degree of injury and suggest a need for improving provider diagnostic skills. Further research looking at the effects of delay on outcomes in this population is needed, specifically for improving care and developing clinical protocols for head-injured patients.

2. In terms of first-responder networks provided for by community volunteers, it would be helpful to determine which communities (rural vs urban, high income vs low income) are most likely to pool together resources for vehicles, infrastructure, fuel, training and other necessary components for a structured-response system. Respondents reported that neighbours already assisted in emergencies, and described a strong sense of community, societal responsibility and civic duty to assist injured persons (this was reinforced by the number of victims transported to healthcare facilities by bystanders). This suggests that there may be high acceptability for first responders to be trained lay people who are known within their community, and further studies with greater generalisability should be conducted to support this.

In summary, our findings characterise an environment of inadequate prehospital care for injured patients, with long delays to definitive care. The results suggest a favourable climate for community-based-response models; however, more research will need to be undertaken to determine acceptability and efficacy of different approaches to EMS in sub-Saharan Africa.

Author affiliations

${ }^{1}$ Emergency Medicine, University of California San Francisco, San Francisco, California, USA

${ }^{2}$ Division of Emergency Medicine, University of Washington-Harborview Medical Center, Seattle, Washington, USA

${ }^{3}$ Emergency Medicine, Muhimbili National Hospital, Dar es Salaam, Tanzania ${ }^{4}$ Muhimbili National Hospital, Dar es Salaam, Tanzania

Twitter Follow Andrew Lim at @andrewglim 
Contributors TR and KK conceived and designed the study. KK obtained funding. KK, BK and NEN designed the interview study guide. KK and NEN conducted the interviews. NEN interpreted the interviews. BK and NEN explained cultural relevance. KK and AGL analysed the data. KK, AGL and TR drafted the article. All authors reviewed and approved the paper. KK and TR take full responsibility for the overall content.

Funding KK received funding for travel and research assistant time for this project from the Kwan Global Health Project Fund, Global Health Sciences, University of California, San Francisco.

Competing interests None declared.

Ethics approval This project was reviewed and approved by the Institutional Review Board of Muhimbili University and the Committee on Human Research of the University of California, San Francisco.

Provenance and peer review Not commissioned; externally peer reviewed.

Data sharing statement No additional data are available.

Open Access This is an Open Access article distributed in accordance with the Creative Commons Attribution Non Commercial (CC BY-NC 4.0) license, which permits others to distribute, remix, adapt, build upon this work noncommercially, and license their derivative works on different terms, provided the original work is properly cited and the use is non-commercial. See: http:// creativecommons.org/licenses/by-nc/4.0/

\section{REFERENCES}

1. Mathers C, Ties B, Ma Fat D. The global burden of disease: 2004 update [Internet]. Geneva: World Health Organization, 2004 [cited 10 Apr 2014]. http://www.who.int/healthinfo/global_burden_disease/ 2004 report update/en/

2. Hyder AA, Allen KA, Di Pietro G, et al. Addressing the implementation gap in global road safety: exploring features of an effective response and introducing a 10-country program. Am J Public Health 2012;102:1061-7.

3. Razzak JA, Kellermann AL. Emergency medical care in developing countries: is it worthwhile? Bull World Health Organ 2002;80:900-5.

4. Anthony DR. Promoting emergency medical care systems in the developing world: weighing the costs. Glob Public Health 2011;6:906-13.

5. Marson AC, Thomson JC. The influence of prehospital trauma care on motor vehicle crash mortality. J Trauma 2001;50:917-20; discussion 920-921.

6. Husum H, Gilbert M, Wisborg T, et al. Rural prehospital trauma systems improve trauma outcome in low-income countries: a prospective study from North Iraq and Cambodia. J Trauma 2003;54:1188-96.
7. Murad MK, Issa DB, Mustafa FM, et al. Prehospital trauma system reduces mortality in severe trauma: a controlled study of road traffic casualties in Iraq. Prehospital Disaster Med 2012;27:36-41.

8. Roudsari BS, Nathens AB, Cameron $P$, et al. International comparison of prehospital trauma care systems. Injury 2007;38:993-1000.

9. Sun $\mathrm{JH}$, Shing $\mathrm{R}$, Twomey $\mathrm{M}$, et al. A strategy to implement and support pre-hospital emergency medical systems in developing resource-constrained areas of South Africa. Injury 2014;45:31-8.

10. Sun JH, Wallis LA. Learning and retention of emergency first aid skills in a violent, developing South African township. Emerg Med J 2013;30:161-2

11. Jayaraman S, Mabweijano JR, Lipnick MS, et al. Current patterns of prehospital trauma care in Kampala, Uganda and the feasibility of a lay-first-responder training program. World $J$ Surg 2009;33:2512-21.

12. Mock CN, Tiska M, Adu-Ampofo M, et al. Improvements in prehospital trauma care in an African country with no formal emergency medical services. J Trauma 2002;53:90-7.

13. Tiska MA, Adu-Ampofo M, Boakye G, et al. A model of prehospital trauma training for lay persons devised in Africa. Emerg Med $J$ 2004;21:237-9.

14. Abdallah S, Heinzen R, Burnham G. Immediate and long-term assistance following the bombing of the US Embassies in Kenya and Tanzania. Disasters 2007;31:417-34.

15. Tanzania: Health Systems 2020 [Internet]. USAID; 2007. http://www. healthsystems2020.org/section/where_we_work/tanzania

16. Schmid T, Kanenda O, Ahluwalia I, et al. Transportation for materna emergencies in Tanzania: empowering communities through participatory problem solving. Am J Public Health 2001;91: 1589-90.

17. Kwesigabo G, Mwangu MA, Kakoko DC, et al. Tanzania's health system and workforce crisis. J Public Health Policy 2012; 33(Suppl 1):S35-44.

18. World Bank Databank: World Development Indicators [Internet] 2006 [cited 25 Mar 2014]. http://data.worldbank.org/indicator/SH. MED.NUMW.P3

19. Hsia RY, Mbembati NA, Macfarlane S, et al. Access to emergency and surgical care in sub-Saharan Africa: the infrastructure gap. Health Policy Plan 2012;27:234-44.

20. Reynolds $\mathrm{T}$, Sawe $\mathrm{H}$, Lobue N, et al. 107 Most frequent adult and pediatric diagnoses among 60,000 patients seen in a new urban emergency department in Dar es Salaam, Tanzania. Ann Emerg Med 2012;60(4 Suppl):S39.

21. Charmaz K. Constructing grounded theory. 1st edn. Thousand Oaks, CA: Sage Publication, 2012.

22. The World Factbook 2013-2014 [Internet]. Washington DC: Central Intelligence Agency, 2013 [cited 17 Feb 2014]. https://www.cia.gov/ library/publications/the-world-factbook/geos/tz.html

23. Lopez A, Mathers C, Ezzati M. Global burden of disease and risk factors. Washington, DC: World Bank, 2006. 